\title{
Co-Integration of Oil and Commodity Prices: A Comprehensive Approach
}

\author{
Mohcine Bakhat a,b,1 and Klaas Würzburg ${ }^{c}$
}

${ }^{a}$ Business economics department, University Sultan Moulay Slimane (Morocco)

E-mail: mohcine.bakhat@usms.ma

${ }^{\mathrm{b}}$ Research fellow, Economics for Energy, Vigo (Spain)

E-mail:mohcine@uvigo.es

'IESIDE, Business Institute (SPAIN)

E-mail: klaas.wurzburg@ieside.edu

\begin{abstract}
Past research has mainly applied linear cointegration analysis to study the relationship of crude oil prices with the prices of other commodities. However, recent methodological innovations in cointegration analysis allow for a more thorough analysis of the co-movement of commodity prices and detect asymmetric and thresholds co-movements. Following Enders and Siklos [1] and Hansen and Seo [2], we apply threshold cointegration analysis, detecting co-movements that earlier studies based on linear cointegration analysis could not detect. We find that adjustments to positive and negative deviations from the long-run equilibrium are asymmetric for copper, food and agricultural raw materials in the short-run. Moreover, the adjustments for aluminum and nickel are symmetric. The price Granger causalities behave as expected for metals and agricultural raw material prices. Food prices, however, behave differently. In sum, the results of this paper underscore the importance of consistently testing nonlinear cointegration and point out the complex interactions that take place between the markets of oil and other commodities.
\end{abstract}

Keywords. linear, threshold, cointegration, metals, raw materials, agriculture

\section{Introduction}

There is remarkable interest in the relationship between the prices of oil and other commodities because there is an urgent need to understand the key characteristics and determinants of long-term commodity price movements, especially with respect to the conditions under which the recent boom occurred. The oil market has experienced high price levels and volatility since the first oil crises back in the 1970s. In the last few years record oil prices and climate-change-related interest in biofuels have intensified the quest for answers in this area, especially due to concerns on growing food prices $[3,4,5]$. High commodity prices, whether or not related to oil prices, have obvious effects on purchasing power and economic growth [6,7]. In this paper we look at the behavior of commodity prices by using a consistent cointegration analysis.

Since the seminal paper of Balke and Forby [8] on nonlinear cointegration, many empirical studies have demonstrated nonlinear and asymmetric adjustments to a longrun equilibrium in many economic time series $[9,10]$. The statistical concept of linear cointegration, as originally defined, refers solely to linear combinations of variables linked through a long-run equilibrium relationship. However, this standard cointegration

\footnotetext{
${ }^{1}$ Corresponding Author, E-mail: mohcine.bakhat@usms.ma
} 
technique fails to capture real world economic phenomena such as the possible impact of market frictions, asymmetric information and transaction costs on the adjustment to the long-run equilibrium. Threshold cointegration, as proposed by Balke and Forby [8] includes the discrete adjustment to long-run equilibrium. In their model, the cointegrating relation between two variables is inactive within a certain threshold and because of this, the variables do not adjust to deviations from the equilibrium. Adjustment only takes place when deviations become large and exceed the threshold. Omitting the presence of nonlinear components, like threshold effects in long-run equilibrium, can lead to misinterpretations of equilibrium relationships because the cointegrating vector will no longer be consistently estimated [11].

In dealing with nonlinear long-run equilibrium models, two issues are interwoven. One is whether or not nonlinearity exists, and the other is whether there is a long-run relationship. The approach considered by Balke and Fomby [8] and later by Hansen and Seo [2] is based on a two-step analysis in which the linear no cointegration null hypothesis is first examined against the linear cointegration alternative. Then the linear cointegration null hypothesis is tested against the threshold cointegration alternative. However, in the presence of nonlinearity the linear test in the first step in this approach tends to fail in rejecting the null of no cointegration. Furthermore, the inability to reject the null in a linear cointegration test does not necessarily imply the absence of a longrun relationship since the possibility of nonlinear cointegration still remains [12]. The second step of the procedure testing for nonlinearity can also pose a problem when cointegration does not hold and the cointegrating vector is unknown. In this regard, the Enders and Siklos [1] approach provides additional crucial information because it formally tests for the joint hypothesis of the absence of both nonlinearity and cointegration.

This paper adopts the discrete two-regime threshold cointegration approach and uses the approaches developed by Hansen and Seo [2] and Enders and Siklos [1] jointly to test for threshold behavior between oil and commodity markets. Hence, unlike most previous studies that retained the usual linear cointegration framework or omitted the importance of the power of the tests in the analysis of threshold cointegration, this paper aims to study oil-commodity linkages within linear and nonlinear frameworks. To this end, it uses a battery of tests that provides more accurate information than most previous research. The paper examines the threshold cointegration relationship between crude oil and a set of different commodities. Given that the nexus of prices of crude oil and other commodities extends to different markets that operate under different constraints (especially the food and agricultural raw material markets) the study explicitly considers aluminum, nickel, copper and natural gas. Furthermore, and for the sake of methodology's illustration the respective aggregated price indexes of food, beverages and agricultural raw materials1 are also considered.

This paper is organized as follows. After this introduction, Section 2 presents the literature review. Section 3 discusses the methodology, data description and the empirical results and, finally, Section 4 provides the main discussions and conclusions. 


\section{Literature review}

Several techniques were used in the economic literature to study the link between crude oil price and commodity prices so far. Most previous research on price transmission analysis has applied linear cointegration analysis based on Johansen, Breitung and ARDL approaches including Granger causality. In addition, the studies that apply these methods focus only on certain categories of commodities (like food or metals).

In the food category Abdel and Arshad [13], based on Johansen cointegration and Granger Causality test, identify a cointegration relationship between crude oil and all the four vegetable oils studied. Using the same technique Zhang et al. [14] look at the price relationship of three different fuels with five standard food commodities. They do not find a cointegrating relationship between energy and food commodities. Yu et al. [15] found a similar result for four major traded edible oil prices. However, based on Johansen cointegration and Granger causality tests, they also find that edible oil markets are well interlinked in the contemporaneous time. In the same line, Esmaeili and Shkoohi [16] construct a principal component of prices of different food commodities. They study the Granger causality between the food component and the oil price, among others, and they do not find a direct relationship between the oil price and the food price component. Other authors use the ARDL approach to study cointegration relations between commodities. For example, Sari et al. [17] investigate the energy-grain nexus (crude oil, gasoline, ethanol, corn, soybeans and sugar) focusing particularly on future prices. They identify dependencies that only partially comply with the general view that causal relationships within the energy grain nexus flow from the oil price to the price of gasoline, ethanol and corn. Chen et al. [18] find that the change in the price of each crop price is significantly influenced by changes in crude oil prices and other grain prices during the period extending from early 2005 to mid 2008.

Research on the relationship between oil and natural gas prices is usually carried out within the context of market integration. Cointegration tests are generally applied within a framework of Johansen and Breitung. Brown and Yücel [19] and Villar and Joutz [20] find the prices of natural gas and crude to be cointegrated, and also point out that the price of natural gas reacts to the price of crude oil. Hartley et al. [21] detect an indirect relationship between crude oil and natural gas through the price of residual fuel oil. Panagiotidis and Rutledge [22] study whether oil and gas "decoupled" during the post market deregulation period (1996-2003). They find that both prices are cointegrated before and after liberalization efforts in the UK gas market. In related work, Asche et al. (2006) find cointegration between natural gas and crude oil prices in the UK market after natural gas deregulation, with crude oil prices leading those for natural gas. Relying on daily ICE futures prices of gas and Brent for five contracts, Westgaard et al. [23] find that a long-term relationship exists between prices depending on the length of the contracts.

Oil prices are also suspected to influence commodities other than just food and energy. Chaudhuri [24] argues that oil prices potentially influence the price of other commodities as long as oil is used in the production process and points out that oil price drives an index composed of different commodity prices (including food, metals, and other consumption goods). Moreover, oil price changes affect real exchange rates and 
the industrial production of (developed) countries that, in turn, affect the world demand for commodities [24].

However, on the analysis of price linkages between oil and commodities most of the literature concentrates on agricultural commodities or on a reduced group of commodities, and only few studies use threshold cointegration in their analysis. Peri and Baldi [5] apply cointegration analysis based on Hansen and Seo [2] on a group of food commodities and find that the cointegration relation of rapeseed and diesel prices is a case of threshold integration. Sunflower oil and soybean oil prices are found to have no cointegration relation with diesel, although Peri and Baldi [5] do not apply the Ender and Siklos test to check whether these two series do feature threshold cointegration. Natanelov et al. [4] use threshold analysis based on Hansen and Seo [2] to investigate the price relationship of future contracts of crude oil, gold and eight food commodities. They find that only cocoa, wheat and gold move together with crude oil in the long-.run over the entire sample period. Hammoudeh et al. [25] investigate the cointegration of future and spot prices for the same commodity. They apply both the method of Hansen and Seo and that of Enders and Siklos but, since they only study cointegration between future and spot prices of the same commodities, they do not report results on comovements of different commodities.

In contrast to earlier research, this paper will look at a wide range of commodities following a comprehensive procedure that covers linear and nonlinear (Threshold) cointegration. The combination of different cointegration tests, applied in this study and described thoroughly in the next section, yields the maximum detail about the co-moving dynamics of data series that contemporary cointegration analysis can provide. We have no knowledge of a study that has ever applied a system similar to that of commodity price pairs.

\section{Methods, data and tests results}

Four hypotheses are possible in threshold cointegration models: linear no cointegration, threshold no cointegration, linear cointegration, and threshold cointegration. The methodology applied in this paper starts by testing linear cointegration. If linear cointegration is found between two price series, then the results are contrasted with the Hansen and Seo test, which infers whether this cointegration relationship is indeed a linear or an asymmetric/threshold. In case the initial linear cointegration tests finds 'no cointegration', the Ender and Siklos cointegration test can be applied to test the null of linear no cointegration against the alternative of threshold cointegration. Hence, in our analysis two cointegration tests are always applied to each pair of price series. The linear cointegration test is always performed to start with, followed by an asymmetric cointegration test that, depending on the finding of the initial linear test is either based on Hansen and Seo [2] or Enders and Siklos [1].

\subsection{Methods}

\section{Linear cointegration}

In order to test the presence of linear cointegration between oil price and commodities prices we employ the technique of Johansen [26]. The first requirement of cointegration 
is that time series variables must be integrated of the same order. Therefore, several unit roots tests are performed for each of the commodity prices. The cointegration requires pre-testing the order of integration of the variables through the unit root tests. For this purpose, Augmented Dickey Fuller (ADF), Phillips and Perron (PP) and the Breitung test were applied, with the latter test being consistent to structural breaks. Then we follow the procedure proposed by Johansen [26] to test for linear cointegration. ${ }^{2}$

\section{Threshold cointegration}

Two methods are applied to study the existence of threshold cointegration or longrun relationships among the variables in the presence of asymmetry in the adjustment process. The first method is the one proposed by Hanson and Seo [2]. It is applied when there is evidence of linear cointegration from the Johansen and Breitung tests. However, the Enders and Siklos [1] method is applied when the Johansen and Breitung tests indicate the absence of linear cointegration. The two methods have different specifications. The first method fits only the long-run adjustments while the second method accommodates for both short- and long-run adjustments. The second method furthermore permits us to examine both threshold autoregressive TAR and momentum threshold autoregressive M-TAR, while the first is appropriate only for TAR. Furthermore, the null hypotheses to be tested are different for each method. We test the null of no cointegration against the alternative of threshold cointegration using the EnderSiklos method. On the other hand, we use the Hansen and Seo LM statistic to test the null of linear cointegration versus the threshold cointegration. If cointegration exists, the two methods provide us with information regarding the adjustment to long-run equilibrium, that is, we explore the co-movements between the oil price and the commodity prices over time, while we allow for asymmetric adjustments toward the long-run equilibrium. ${ }^{3}$

\subsection{Data}

This methodology is applied to the commodity price indexes available in the International Monetary Fund database. Prices of the following commodities were taken and included in the analysis: crude oil, aluminum, nickel, copper and natural gas and the aggregated price indexes of food, beverages and agricultural raw materials, respectively. Previous research has shown that the pattern of commodity prices has changed with the new millennium. Therefore, if the investigated time span covers the period prior to the year 2000, this may negatively affect the quality of the estimation results. Our series consists of monthly data from January 2000 to April 2011, to avoid possible distortions from these different data patterns (This gives 114 observations).

\footnotetext{
${ }^{2}$ For more details of the methodology refer to the article of Johansen [26]

${ }^{3}$ Details of the methodology are reported in the articles of Hansen and Seo [2], Ender and Siklos [1]
} 


\subsection{Tests results}

The combined results of the three tests suggest that the commodities prices time series are, all in all, integrated of order one I(1). Therefore, we go on and conduct the cointegration analysis. ${ }^{4}$

\section{Linear cointegration}

The results from the Johansen test and Breitung test reveal that linear cointegration exists, at least a 5\% significance level, for the pairs natural gas-crude oil and coppercrude oil. In addition, the results suggest the absence of cointegration between crude oil price and the following commodity prices: nickel, aluminum, agricultural raw materials, food and beverages, respectively. ${ }^{5}$

\section{Threshold cointegration and the asymmetry tests}

The presence of threshold cointegration is analyzed using the Ender and Siklos [1] and the Hansen and Seo [2] methods. Starting with the Ender-Siklos method first, we find that there is no evidence of the presence of cointegration between the crude oil price and the beverages price. In addition, the $\Phi_{\mu}$ statistics indicate the existence of a pair-wise threshold cointegration between oil price and nickel, aluminum, food, and materials at $1 \%$, and $5 \%$ significance level, respectively. We then assess whether the adjustment to the long-run equilibrium is symmetric or asymmetric. In other words, we test if the comovement towards the long-run equilibrium between the oil price and each of the commodity prices occur at different speeds relative to their being below or above the threshold. The test results suggest asymmetric adjustments for food and agricultural raw materials, whereas symmetric adjustments are shown for nickel and aluminum.

For the crude oil-aluminum pair, the point estimates for the price adjustment show that deviations from the long-run equilibrium would be eliminated at $10.7 \%$ in a month, regardless of the sign of the shocks. In other words, it would take 9 months to eliminate deviation from the long-run equilibrium for either positive or negative deviations. Similarly, about the same amount of time is required to fully eliminate long-run deviations for the crude oil-nickel pair.

Applying Hansen-Seo method, which uses the LM threshold test, a threshold cointegrating relationship is found between the oil price and the copper price at a $10 \%$ significance level, while no threshold cointegration is detected for natural gas. Hence, the oil prices and gas prices are linearly cointegrated and co-move together towards the long-run equilibrium. Similarly, the Hansen-Seo method allows us to test if the adjustments towards long-run equilibrium are symmetric or asymmetric. Subsequently, the pair-wise combination of the oil price with copper co-moves towards the long-run equilibrium at different speeds that correspond either to being below or above the threshold. In other words, the adjustment towards the respective long-run equilibrium is asymmetric.

${ }^{4}$ Results are available upon request from the authors

${ }^{5}$ The lag order of the VAR specification is obtained by using Akaike (AIC), Schwarz (SC) and Hannan and Quinn (HQ) information criteria. We should also recall that, so far, these results are preliminary and have to be corroborated with threshold cointegration tests. 
So far, we can summarize the results as follows: First, no cointegration relationship is found between the crude oil price and the price of beverages, which means that no direct effect exists between the oil market and the beverage markets. Second, the crude oil price is linearly cointegrated with the price of natural gas and this relation is featured with a high speed of adjustment to long-run equilibrium. Third, each of aluminum and nickel prices are threshold cointegrated with crude oil prices, and the price responses to either positive or negative shocks are symmetric. In contrast, the copper price shows a different pattern due to the presence of the asymmetric threshold cointegration, characterized with a faster speed of adjustment when deviations are above the threshold than below it. Finally, asymmetric threshold cointegration is also found between the crude oil price and the prices of food and agricultural raw materials price, respectively. The speeds of adjustment to long-run equilibrium in each case are subject to the sign of the shocks.

\section{Results of the error correction model}

We first start with the oil and natural gas pair, which exhibits a linear cointegrating relationship. The vector error-correction model yields a high parameter estimate (-1.36). This indicates a strong relationship between oil and natural gas prices. Besides, the statistical significance of the speed of the adjustment coefficient shows that the adjustment towards the long-run equilibrium occurs at the rate of $12.5 \%$ per month. The Granger causality outcomes show that crude oil and natural gas prices move together in the long-run with a significant bi-directional causality effect. In the short run, crude oil price leads the prices of natural gas pointing to a close integration between these markets.

Based on the results of the Hansen and Seo [2] threshold VEC, models are specified to assess the asymmetric dynamic behavior in the pairs that are threshold cointegrating. Each of the TVECM is estimated using the negative log-likelihood estimator and the selection of the lag order is determined by AIC and BIC. The parameter estimates are estimated for each regime and their t-statistics are reported in parentheses, where the heteroskedasticity- consistent (Eicker-White) standard errors are considered.

For crude oil, when the error correction term exceeds the threshold value, we see the flat near-zero error-correction effect. Whilst in the first regime $\left(\omega_{t-1} \leq-1.576\right)$, the response to crude oil price changes is much faster. For copper equations, the adjustment to the long run equilibrium is faster when the error correction term is below the threshold value $\left(\omega_{t-1} \leq-1.576\right)$, that is, when copper prices decrease or crude oil prices increase. The response of the error-correction effects to copper is significantly larger than the response of crude oil price changes in the second regime $\left(\omega_{t-1}>-1.576\right)$.

Based on the Ender-Siklos model, the asymmetric correction model with threshold cointegration is estimated for the pairs: crude oil- aluminum, crude oil- copper, crude oil-food and crude oil-agricultural raw materials. AIC and BIC were used to determine the optimal lag length of the model and the residual autocorrelation was analyzed with the Ljung-Box Q statistic.

The results suggest that there is momentum equilibrium adjustment asymmetry for the cases of food and agricultural raw materials. In addition, results show that both food and oil prices respond to deviations from the long-run equilibrium below the threshold in the short term; the food price adjustment is very slow in this regime. In other words, food prices respond to the negative deviations by $3.7 \%$ in a month, or alternatively 
negative deviations take about 27 months to be fully eliminated. Similarly, in the shortrun, it is the price of agricultural raw materials and not the crude oil price, which responds to deviations from the long-run equilibrium below the threshold with $14 \%$ of the deviations eliminated each month (this results from a decrease in agricultural raw material prices, or equivalently, an increase in crude oil prices). Furthermore, the F statistics show that the cumulative effects in aluminum; nickel and agricultural raw material equations, respectively, are asymmetric.

The hypotheses of Granger causality between crude oil and each one of the commodities were examined with F-tests. Results show a significant Granger causality at $10 \%$ level between crude oil and aluminum and copper, respectively, and at 5\% level between crude oil and agricultural raw material, and at $1 \%$ level between crude oil and food (crude oil $\rightarrow$ aluminum; crude oil $\rightarrow$ copper; food $\rightarrow$ crude oil; crude oil $\rightarrow$ agricultural raw materials). Yet, no Granger causality is detected between crude oil and beverages. Thus, in the short-term it seems that the prices of metals (aluminum and nickel) and agricultural raw material have depended on the crude oil price. On the other hand, food appears to be leading the price movement of crude oil, with oil prices adjusting to deviations from long-run equilibrium.

\section{Conclusions}

In this paper we investigate price relationships of crude oil and different types of other commodities applying a system of different cointegration tests. This combination of different cointegration analyses confirms the argument that non-linear and threshold cointegration techniques better represent real markets where frictions, asymmetric information, transaction costs cause non-linear outcomes [10,4,5]. For the price pairs investigated in this paper linear cointegration tests fail to detect any relation between crude oil price and most prices of the commodities. However, when non-linear cointegration analysis as proposed by Enders and Siklos [1] and Hansen and Seo [2] is applied, we find that the estimated thresholds in the case of aluminum, nickel, copper, food and agricultural raw materials are not zeros. We also identify asymmetric cointegration between the crude oil price and the prices of copper, and food and agricultural raw materials, respectively.

Results for the metals category show that each of the aluminum and nickel prices are threshold cointegrated with crude oil prices. The Granger causality tests indicate that the crude oil price leads the prices of aluminum and nickel. Hence, global investors can predict the prices of aluminum and nickel by following fluctuations in the oil prices. In addition, we find that price responses are symmetric in the sense that a shock to crude oil prices of a given magnitude would give rise to the same response in aluminum and nickel respectively, regardless of whether the shock reflected a price increase or price decrease, and deviations after the shocks are digested in roughly 10 months. Copper shows a different asymmetric adjustment; it yields a faster speed of adjustment when deviations are above the threshold $\left(\omega_{t-1}>-1.576\right)$ rather than below it $\left(\omega_{t-1} \leq-1.576\right)$. Asymmetry price transmission revealed that pair-wise adjustments of the oil and copper prices are faster when crude oil price decreases than when it increases. 
For the relation between crude oil and natural gas we find that the crude oil price is linearly cointegrated with the natural gas price. The main result from the VECM approach is the relatively high magnitude of the parameter estimate (-1.36), which means that a strong relationship exists between crude oil and natural gas prices. On the other hand, the speed of the adjustment coefficient shows that about $12.5 \%$ of the adjustment towards long-run equilibrium would take place in each month. The Granger tests reveal that crude oil prices and natural gas prices have been tied up in the long run; short-run shocks can be transferred from the crude oil market to the gas market. These findings do not support the hypothesis that recent developments in natural gas technologies (shale gas, reduced transport costs) would unlink natural gas and crude oil prices. It seems that the link is still strong, much in line with the theoretical substitution relationship between the two fuel types. Previous research [19,21] extensively discussed the possible reasons for this finding.

Results also show that food prices are threshold cointegrated with the crude oil price, underlining the strong price interdependence of food and crude oil for the period under study. Moreover, the different outcomes of the Granger causality test and the adjustment speed asymmetries in this category highlight the complex relationship between food and crude oil prices: The Granger causality showed that the price of food led the crude oil price. That is, fluctuations of food prices are likely to be transmitted to the crude oil market. The results from the asymmetric speed adjustments show persistence of food prices when the crude oil price increases (deviations are eliminated at a rate of $3.7 \%$ per month). This particular interaction is interesting and some authors credit it to the increasing role of the biofuel market during the last decade [4,5]. Similarly, agricultural raw material prices show the presence of momentum equilibrium adjustment asymmetry and adjust faster when deviations are below threshold. Results also show a Granger causality running from agricultural raw material prices to crude oil prices, which recommends further detailed research into the linkages between the prices of each agricultural raw material and crude oil prices.

Our work provides a detailed analysis about non-linear cointegration relationships between the crude oil price and prices of a group of different commodities. The different outcomes can provide insight on price movements and their complex interdependences. However, it is relevant to mention that other factors as regulatory interventions, general economic conditions (crises) and other exogenous impacts contribute to the uncertainty and volatility of commodities markets, and increase the complexity of price dynamics between crude oil and other commodities. Therefore, advanced analysis that represents real conditions on markets in the most appropriate way are required to better understand these price dynamics and help policy-makers and other actors in these markets to take the correct decisions. 


\section{References}

[1] W., Enders, P. L., Siklos, Cointegration and Threshold Adjustment, Journal of Business \& Economic Statistics, 19(2), (2001), 166-76.

[2] B.E., Hansen, B., Seo, Testing for two-regime threshold cointegration in vector error-correction models. Journal of Econometrics, 110, (2002) 293-318.

[3] K., Balcombe, A., Bailey, J., Brooks, Threshold Effects in Price Transmission: The Case of Brazilian Wheat, Maize, and Soya Prices, American Journal of Agricultural Economics, 89(2),( 2007), p. 308 323.

[4] V., Natanelov, M.J., Alam, A.M., McKenzie, G., Van Huylenbroeck, Is there co-movement of agricultural commodities futures prices and crude oil? Energy Policy,39, (2011), 4971-4984.

[5] M., Peri, L., Baldi, Vegetable oil market and biofuel policy: an asymmetric cointegration approach, Energy Economics, 32 (3), (2010), 687-693.

[6] K., Chaudhuri, Long-run prices of primary commodities and oil prices, Applied Economics, 33, (2001), 531-538.

[7] Z., Zhang, L., Lohr, C., Escalante, M., Wetzstein, Food versus fuel: what do prices tell us? Energy Policy $38,(2010)$, p. 445-451.

[8] N.S., Balke, T.B., Fomby, Threshold cointegration. International Economic Review 38, (1997), p. $627-$ 645.

[9] M.C., Lo, E., Zivot, Threshold Cointegration and Nonlinear Adjustment to the Law of One Price. Macroeconomic Dynamics 5(4),(2001), p. 533-576.

[10] C.C., Douglas, Do gasoline prices exhibit asymmetry? Not usually! Energy Economics 32(4), ( 2010), p.918-925.

[11] J., Gonzalo, J.Y., Pitarakis, Threshold effects in cointegrating relationships. Oxford Bulletin of Economics and Statistics 68, (2006), p. 813-833.

[12] M., Seo, Bootstrap testing for the null of no cointegration in a threshold vector error correction model. Journal of Econometrics 134, (2006), p. 129-50.

[13] H.A., Abdel, F.M., Arshad, The impact of petroleum prices on vegetable oils prices: evidence from cointegration tests. Oil Palm Industry Economic Journal 9(2), (2009), p. 31-40.

[14] Z., Zhang, L., Lohr, C., Escalante, M., Wetzstein, Food versus fuel: what do prices tell us? Energy Policy 38, (2010), p. 445-451.

[15] T.H., Yu, D.A., Bessler, S. Fuller, Cointegration and Causality Analysis of World Vegetable Oil and Crude Oil Prices. Selected Paper prepared for presentation at the American Agricultural Economics Association Annual Meeting, Long Beach, CA July 23-26 (2006).

[16] A., Esmaeili, Z., Shokoohi, Assessing the effect of oil price on world food prices: Application of principal component analysis, Energy Policy 39, (2011), p. 1022-1025.

[17] R., Sari, S., Hammoudeh, C.L., Chang, M., McAleer, Causality between market liquidity and depth for energy and grains, WP SSRN, (2011).

[18] Chen, S.T., Kuo. H.I., Chen, C.C., 2010. Modeling the relationship between the oil price and global food prices, Applied Energy 87, p. 2517-2525.

[19] S., Brown, M. Yücel, What drives U.S. Natural Gas Prices? presented at the USAEE 26th Annual Conference. Ann Arbor, Mi, (2006).

[20] J., Villar, F., Joutz, The Relationship Between Crude Oil and Natural Gas Prices. EIA manuscript, October 2006, (2006).

[21] P.R., Hartley, K.B., Medlock, J.E., Rosthal, The relationship of natural gas to oil prices, Energy Journal 29, (2008), p. 47-66.

[22] T., Panagiotidis, E., Rutledge, Oil and gas markets in the UK: evidence from a cointegrating approach. Energy Economics 29, (2007), 329-347.

[23] S., Westgaard, M., Estenstad, M., Steim, S., Frydenberg, Co-integration of ICE gas oil and crude oil futures. Energy Economics 33, (2011), p. 311-320.

[24] K., Chaudhuri, Long-run prices of primary commodities and oil prices, Applied Economics 33,( 2001), p. 531-538.

[25] S., Hammoudeh, L.H., Chen, B., Fattouh, Asymmetric adjustments in oil and metals markets, Energy Journal 31(4), (2010), p. 183-202.

[26] S., Johansen, Likelihood Based Inference in Cointegrated Vector Error Correction Models, Oxford University Press, Oxford, (1995). 